\title{
El imaginero Alonso de Covarrubias en Roma
}

\author{
The sculptor Alonso de Covarrubias in Rome
}

\author{
Dr. Juan José CLOPÉS \\ Universidad Complutense de Madrid \\ Dra. María Elena AGUADO \\ Universidad de Castilla La Mancha
}

\begin{abstract}
Resumen: Todos los estudios sobre Alonso de Covarrubias, pese a considerarle uno de los introductores del arte a lo romano, le niegan el conocimiento directo de las obras que se estaban realizando en Italia, limitando su formación en el arte del Renacimiento al manejo de tratados y estampas. En este trabajo se documenta su presencia en Roma en fechas muy tempranas, en el contexto del patrocinio ejercido por doña Teresa Enríquez, señora de Torrijos, sobre la Cofradía del Santísimo Sacramento de San Lorenzo in Damaso.

Abstract: All the studies on Alonso de Covarrubias, despite considering him to be one of the introducers of Roman art, deny him direct knowledge of the works that were being produced in Italy, limiting his training in Renaissance art to the handling of treatises and prints. This work documents his presence in Rome at an exceedingly early date, in the context of the patronage exercised by Doña Teresa Enríquez, lady of Torrijos, over the Confraternity of the Blessed Sacrament of Saint Lorenzo in Damaso.
\end{abstract}

Palabras claves: Alonso de Covarrubias, Teresa Enríquez, Roma, siglo XVI, San Lorenzo in Damaso, Santísimo Sacramento.

Keywords: Alonso de Covarrubias, Teresa Enríquez, Rome, 16th century, Saint Lorenzo in Damaso, Blessed Sacrament.

\section{Sumario:}

I. De lo moderno a lo romano.

II. Torrijos y doña Teresa Enríquez. 
III. Testimonio notarial de las obras de San Lorenzo in Damaso.

IV. Conclusión.

V. Fuentes y Bibliografía.

Recibido: septiembre 2021.

Aceptado: noviembre 2021. 


\section{DE LO MODERNO A LO ROMANO}

Según Azcárate, el estilo hispano-flamenco que se desarrolla durante el reinado de los Reyes Católicos, y en torno a su Corte, "supone la armónica fusión de las formas y sentir estético que constantemente han informado nuestro pasado medieval. Aún más, en la evolución de este estilo se halla el fundamento de nuestra peculiar arquitectura renacentista"1.

Esa dualidad y peculiaridad sin duda marca la obra de Alonso de Covarrubias (¿Torrijos? c. 1488 - Toledo 1570)², que aprenderá las formas góticas en el

${ }^{1}$ AZCÁRATE RISTORI, J.M., "Sentido y significación de la arquitectura hispanoflamenca en la corte de Isabel la Católica", Boletín del Seminario de Estudios de Arte y Arqueología [en adelante BSAA] (Valladolid), 37 (1971) 202.

${ }^{2}$ La fecha de su nacimiento fue apuntada por Agustín Rodríguez y Rodríguez, gracias a una información testifical realizada en Toledo el 14 de febrero de 1558: "Uno de los testigos fue el célebre maestro de obras Alonso de Covarrubias, "de hedad de setenta años, poco más o menos"”, en RODRÍGUEZ Y RODRÍGUEZ, A., "Santa Teresa de Jesús en Toledo", Toletum (Toledo), 14-15 (1923) 13-14. Señala Llaguno y Amirola que "Alonso salió joven de su país y estableciéndose en Toledo casó con María Gutiérrez de Egas, natural de aquella ciudad, donde residían en la parroquia de S. Andrés cuando a 25 de julio de 1512 les nació su hijo el célebre D. Diego de Covarrubias y Leiva [...] las Memorias para la vida del Sr. presidente Covarrubias, originales de su letra [...] dice así: Yo, el Dr. Diego de Covarrubias de Leiva, hijo de Alonso de Covarrubias y de Mari Gutiérrez de Egas, nací en Toledo en la parroquia de Sant Andrés, domingo, a mediodía, 25 de julio, día de Santiago, anno de MDXII. Vine a Salamanca por el mes de octubre del anno de MDXXIII, acabé de aprender a leer y escrebir en casa de Pedrarias a Sant Isidro [...] Llegué a Salamanca (año MDLIX) ocho días después de fallescido el Racionero Juan de Covarrubias y Leiva, mi señor tío, hermano de mi padre, el cual me crió y dio de comer todo el tiempo que estuve en Salamanca [...] Fallesció mi señora y madre Mari Gutiérrez de Egas martes, a 21 de junio de 1569 en Toledo. R.I.P.A. Falleció mi señor y padre Alonso de Covarrubias en Toledo, sábado, a 11 de marzo del anno 1570", en LLAGUNO Y AMIROLA, E., Noticias de los arquitectos y arquitectura de España desde su restauración, Madrid 1829, t. I., Tomo 1, pp. 183-184. García Rey fue el primero en aportar de manera sistemática documentos sobre su vida y obra, base para el conocimiento del artista, y cuya transcripción ha sido germen de la gran mayoría de estudios posteriores. Sus trabajos se encuentran publicados en diferentes números de la revista Arquitectura: GARCÍA REY, V., "La puerta nueva de Bisagra", Arquitectura (Madrid), 37(1922)191-195 y "La portada de la iglesia del monasterio de San Clemente el Real de Toledo", en Arquitectura (Madrid) 79 (1925) 249-254. Así mismo con el título: "El famoso arquitecto Alonso de Covarrubias (datos inéditos de su vida y obra)", en Arquitectura (Madrid), en los números: 97 (1927 167-175; 98 (1927) 207-212; 101 (1927) 311-319; 103 
ambiente artístico toledano en el que da sus primeros pasos e irá evolucionando a las novedades artísticas importadas desde Italia, hasta convertirse en uno de los máximos exponentes del arte a lo romano ${ }^{3}$.

(1927) 375-380; 104 (1927) 415-420; 105 (1928) 3-4; 107 (1928) 95-99; 110 (1928) 202-203; 111 (1928) 236-237; 112 (1928) 268-269; 113 (1928) 297-299; 114 (1928) 331. Al respecto también contamos con las aportaciones de MIRANDA CALVO, J. "Alonso de Covarrubias en los documentos", Militaria (Madrid), 2 (1990) 103-116; "Aspectos inéditos de la obra de Alonso de Covarrubias en los documentos", Beresit (Toledo), 3 (1989) 249-259, y PEDRAZA RUIZ, E., "Covarrubias en los documentos del Archivo Municipal de Toledo", Toletum (Toledo) 25 (1990) 27-36. Algunos trabajos están dedicados a obras concretas: MUÑOZ PÁRRAGA, M.C., "Nuevos datos sobre la obra de Alonso de Covarrubias en Sigüenza", en Anales seguntinos (Siguenza), 1 (1984) 89-92; IPIENS MARTÍNEZ, E., "La construcción de la iglesia de Albalate de Zorita (Guadalajara), con trazos de Alonso de Covarrubias", en Archivo Español de Arte [en adelante AEA] (Madrid), 225 (1984) 96-108; SÁNCHEZ-ROBLES BELTRÁN, J. "Las escaleras postmedievales: Alonso de Covarrubias y la escalera imperial", en Príncipe de Viana (Pamplona), 12 (1991) 287-292; GARCÍA LOPEZ, A., "Alonso de Covarrubias, autor del Palacio Ducal de Pastrana (documentación sobre construcción, de 1542 a 1553)", Wad-al Hayara (Guadalajara), 19 (1992) 57-74; MARÍAS FRANCO, F., "La capilla mayor de San Román de Toledo: ¿Un templo de Zorobabel al romano?, en BSAA (Valladolid), 74 (2008) 89-112; FERNÁNDEZ COLLADO, A., "Alonso de Covarrubias y el patio de invierno del Palacio Arzobispal", en $L o$ uno y lo múltiple: homenaje a Félix del Valle y Díaz, Toledo 2009, pp. 551-564; MARTÍNEZ MONTERO, J. "Nuevas aportaciones a la historia constructiva de la escalera del Hospital de santa Cruz en Toledo", en De arte (León), 12 (2013) 137-152; SEGURA FERRER, J. M y VALERO SEGURA, C., "La capilla mayor y el crucero de la iglesia de San Jerónimo de Baza", en Cuadernos de arte de la Universidad de Granada (Granada), 48 (2017) 51-71. Otros estudios son más generales: QUILEZ MARTÍ, J., “Alonso de Covarrubias”, Wad-al-Hayara (Guadalajara), 11 (1984) 343-348; CANO DE GARDOQUI GARCÍA, J. L., "Precisiones sobre Alonso de Covarrubias, maestro mayor de las Obras Reales (1488-1570)", en Estudios de historia del arte: homenaje al profesor de la Plaza Santiago, Valladolid 2009, pp. 81-86; GÓMEZ GÓMEZ, J. M., "Toledo y sus creadores; Alonso de Covarrubias", Tendencias Toledo (Toledo), 4 (2013) 29-33. El trabajo más completo sobre el artista es el realizado por SANTOS VAQUERO, A., y SANTOS MARTÍN, A., Alonso de Covarrubias: el hombre y el artífice, Toledo 2003. Uno de los últimos a él consagrados, presentado por su propio autor como la primera biografía del artista, se publicó con motivo del 500 centenario de la Colegiata de Torrijos, LONGOBARDO CARRILLO, J., Alonso de Covarrubias y Leyva: vida y obra del más ilustre hijo de la Villa de Torrijos, Toledo 2018.

3 "Después con el estudio de Bramante y Baltasar Peruzio y Leon Baptista se començó a passar más adelante la obra antigua en modo más artista traxéronla de allá de hazia Levante Siloe y Covarrubias algo mixta, porque en partes mezclavan muchas cosas modernas, por tenerlas por hermosas.[...] Esta obra bárbara puesta ya en su término a començado también en nuestros tiempos a desusarse, introduziéndose de nuevo la obra antigua de los Griegos y Romanos, y aunque en Italia resuscitó antes con la diligencia y estudio de Bramante, maestro mayor de la fábrica de San Pedro de Roma, Baltasar Peruzio y León Baptista Alberto, Architectos celebrados en España, también començó a florescer con la industria del excelente Alonso de Covarrubias, maestro mayor de la fábrica de la cathedral de Toledo y del Alcaçar Real. Padre del famosíssimo doctor don Diego de Covarrubias, presidente del Supremo consejo de su Magestad y Obispo de Segovia, y Diego Siloe, maestro mayor de las fábricas de la Catheral y alcaçar de Granada, que estos començaron esta obra en partes muchas donde fabricaron, aunque siempre con alguna mezcla de la obra moderna, que nunca la pudieron olvidar del todo", en ARFE Y VILLAFAÑE, J., De varia conmensuración para la esculptura y architectura, Sevilla 1585, t. IV, quarto, f. $2 \mathrm{v}-3$. 
La escasez de documentos de su etapa de formación conlleva que esta sea la más desconocida del artista. La mayoría de los autores datan sus comienzos en el año 1509, a las órdenes de los Egas, en torno a las obras de la Colegiata de Torrijos, en la provincia de Toledo. Pero tampoco debemos descartar otras hipótesis, como que pudiera comenzar su aprendizaje en cualquier otro taller activo entonces en la villa, en los edificios patrocinados por la familia Cárdenas. Así, en su primera etapa, que fue como imaginero, realizaría obras al gusto que imperaba en la corte $\mathrm{y}$ al estilo del taller en el que trabajaba, posiblemente de los hermanos Egas. Más tarde llegarían sus primeras obras independientes, ya como cantero, e interpretando las formas que se importaban desde Italia; que con el tiempo resolvería de manera magistral, convirtiéndose en maestro del arte a lo romano.

La introducción en España de esta nueva corriente artística tuvo dos posibles vías. Los artistas que tuvieron la oportunidad de ir a Italia, que asimilaron con más facilidad el nuevo lenguaje, y los que no pudieron y necesitaron recurrir a las fuentes teóricas e iconográficas ${ }^{4}$. Respecto a Alonso de Covarrubias, la historiografía viene manteniendo firmemente la teoría de que nunca viajó a Italia y, por lo tanto, que su conocimiento de los nuevos conceptos artísticos sería adquirido a través de tratados de arte o de los trabajos que estaban desarrollando los maestros que sí habían viajado ${ }^{5}$. García Rey considera que pudo aprender en Toledo, donde su presencia está documentada el año 1512, o en Valladolid, donde pudo conocer la obra escultórica de Berruguete ${ }^{6}$. No obstante, admite la posibilidad de un hipotético viaje a Italia entre los años 1513-1525, basándose en el silencio documental y considerando que en este largo período seguiría en el taller de los Egas ${ }^{7}$. No obstante, la mayoría de los autores especulan con la idea de una formación a través de estampas, grabados y libros; fundamentalmente el tratado las Medidas del Romano de Diego de Sagredo ${ }^{8}$. Santos Vaquero y Santos

\footnotetext{
${ }^{4}$ MORALES A. J., "Tradición y modernidad, 1526-1563”, en NIETO, V., MORALES, A.J. y CHECA, F., Arquitectura del Renacimiento en España:1488-1599, Madrid 1989, p. 120.

5 "Diego de Sagredo, contemporáneo suyo, dice en Las Medidas del Romano, 'que los arquitectos antiguos construyeron soberanos edificios y muchas obras de admirable arquitectura, cuales hoy día muchas de ellas parecen, de donde nunca cesan de sacar muestras, dibujos, medidas, trazas, modelos... que se reparten por todo el mundo'. No sería España la última a donde llegaron estos ejemplares de la antigüedad, por el frecuente trato que con Italia se tenía entonces; ni faltan dentro de ella edificios y ruinas de donde se pudieron sacar otros; y viéndolos Covarrubias, su misma razón le haría conocer las ventajas de aquel modo de edificar, y le movería a imitarle, aunque imperfectamente, como imitan los que tienen acostumbrados los ojos y las manos a otros objetos y otra práctica. Es de creer que en sus principios no tuviese mayores estudios, porque no había en nuestra lengua libro alguno de arquitectura, hasta que en 1526 se publicó el de las Medidas del Romano", en LLAGUNO AMIROLA, E., Noticias de los arquitectos..., t. I, p. 185.

${ }^{6}$ GARCÍA REY, V., Arquitectura, 79..., p. 251.

${ }^{7}$ GARCÍA REY, V., Arquitectura, 97..., p. 171.

${ }^{8}$ Diego de Sagredo es autor del Tratado de arquitectura Medidas del romano necesarias a los oficiales que quieren seguir las formaciones de las basas, columnas, capiteles y otras
} 
Martín consideran que dicho tratado pudo ser el motor del cambio de registros, junto con el conocimiento de los trabajos de Siloé en Salamanca y la influencia de Lorenzo Vázquez ${ }^{9}$. Señalan la iglesia de la Piedad de Guadalajara como el primer edificio en el que interpreta la arquitectura con planteamientos que muestran un claro cambio de estilo ${ }^{10} \mathrm{y}$ destacan que es la primera vez que figura como maestro de cantería ${ }^{11}$, sin la intervención de los Egas, motivo por el que podía tener más libertad, al tiempo que puntualizan que este cambio de registro también se debe los gustos artísticos del cliente, en este caso perteneciente a la familia Mendoza ${ }^{12}$.

Pese al evidente interés y posible vigencia de tales planteamientos, lo cierto es que Alonso de Covarrubias sí viajó a Italia, en 1508, como se expondrá a

piezas de los edificios antiguos, Toledo, Imprenta de Ramón de Petras, 1526. Para conocer más sobre la biografía de este autor y su obra, sugerimos el siguiente enlace en la web de la Real Academia de la Historia http://dbe.rah.es/biografias/5613/diego-de-sagredo, en que Macarena Moralejo Ortega hace una síntesis biográfica donde también aporta información sobre el ambiente en que se gestó dicho tratado y adjunta una extensa e interesante bibliografía al respecto. No obstante, a continuación, hemos creído oportuno actualizar con algunas publicaciones más recientes. GARCÍA FUENTES, J.M., Raices simbólicas y microcosmos en el dibujo de proporciones humanas del tratadista español Diego de Sagredo, Tesis doctoral dirigida por Antonio Bautista Durán, Sevilla 2008; MERINO RODRÍGUEZ, F., Las ediciones parisinas de 1555 de Medidas a lo romano de Diego de Sagredo: propuestas interpretativas", en HUERTA FERNÁNDEZ, S., Actas del séptimo Congreso Nacional de Historia de la Construcción, Santiago de Compostela 2011, t. 2, pp. 907-916; CORREIA DE QUEIRÓS, A.I., "El papel de la arquitectura en el sueño y la importancia del sueño en la arquitectura del siglo XVI: Francesco Colonna y Diego de Sagredo", en Mirando a Clio: el arte español espejo de su historia, Santiago de Compostela 2012, pp. 1822-1831; MORALEJO ORTEGA, M. M., "Sagredo, Diego", en Diccionario biográfico español, 2013, pp. 49-52; LEPRI, N., "Per una traduzione italiana delle Medidas del romano di Diego de Sagredo (1526), Traslationes (Ciudad de Mendoza, Argentina), 6 (20014) 65-77; PITA GALÁN, P., "Conceptos teóricos y estéticos y sus términos asociados en las Medidas del romano de Diego de Sagredo (II): de la naturaleza a la belleza”, en RODRÍGUEZ ORTEGA, N., y TAIN GUZMÁN, M., Teoría y literatura artística en España: revisión historiográfica y estudios contemporáneos, Madrid 2015, pp. 964-985; JACINTO GARCÍA, E.J., "La dimensión tradicional en los primeros tratados de arquitectura españoles: el caso de las "Medidas del romano de Diego de Sagredo' (1526)", en Nuevas perspectivas de la diacronía de las lenguas de especialidad, Alcalá de Henares 2018, pp. 211-228.

${ }^{9}$ SANTOS VAQUERO, A., y SANTOS MARTín, A., Alonso de Covarrubias..., p. 127.

${ }^{10}$ La clave está en que en el contrato "dispone la construcción como una unidad programática, a diferencia de lo que se venía haciendo con anterioridad" y el interés "casi obsesivo por decorar a lo romano; otro punto a destacar es que se estipula que la portada principal debe tener las proporciones de la casa que Lorenzo Vázquez hiciese para la casa de Antonio de Mendoza [...] con el fin de armonizar el conjunto, y el deseo de establecer desde la firma del contrato las dimensiones de planta y alzado" en SANTOS VAQUERO, A. y SANTOS MARTÍN, A., o.c., pp. 129-132.

${ }^{11}$ MORALES A. J., "Tradición y modernidad...”, p. 152.

12 SANTOS VAQUERO, A., y SANTOS MARTín, A., Alonso de Covarrubias..., pp. 128-129. 
continuación. Por entonces era un joven imaginero, y muy probablemente pudo emprender el viaje merced al generoso patrocinio de doña Teresa Enríquez.

\section{TORRIJOS Y DOÑA TERESA ENRÍQUEZ}

Es de suma importancia conocer el ambiente en el que Alonso de Covarrubias se formó como aprendiz en el oficio de imaginero. La mayoría de los autores dan por válido su nacimiento en Torrijos, aunque la documentación existente no es contundente al respecto ${ }^{13}$. Independientemente del lugar de nacimiento cabe la posibilidad de su ascendencia rachela ${ }^{14}$, pues tampoco queda claro el origen de sus padres, y creemos que es posible la existencia de un vínculo entre la villa burgalesa y el oficio familiar de broslador o bordador ${ }^{15}$. Un oficio que

${ }^{13}$ Será García Rey quien aporte el documento que "permite establecer la nueva genealogía" y que contiene "el expediente de información de calidades de Antonio de Covarrubias hecha por comisión de los ilustrísimos señores deán y cabildo de la santa Iglesia de Toledo", en GARCÍA REY, V., Arquitectura, 97..., p. 167, y Arquitectura, 105..., pp. 6 y 7. Coincidimos con Santos Vaquero y Santos Martín en que el documento tampoco es rotundo respecto a los orígenes de sus padres, pues los testigos dan respuestas diferentes e incluso contradictorias en SANTOS VAQUERO, A. y SANTOS MARTÍN, A., Alonso de Covarrubias..., pp. 91-95.

${ }^{14}$ Rachela o Rachelo, gentilicio de Covarrubias, quizás como resabio de su importante judería. Llaguno y Amirola plantea la hipótesis de que Covarrubias, aunque utilizado como apellido, podía ser el lugar de origen de la familia. Considera que el verdadero apellido podía ser Leyva, motivo por el que lo incorporaría a su nombre los hijos del artista, en LLAGUNO AMIROLA, E., Noticias de los arquitectos..., t. I, p. 1. Comparte teoría sobre los orígenes familiares GARCÍA REY, V., en Arquitectura, 97..., p. 169.

15 Tanto su padre como su hermano Marcos eran bordadores. Marcos debió contar con taller en Toledo y trabajó para la Santa Iglesia Catedral. En su taller, también de Juan de Covarrubias, se realizó un terno para el cardenal Cisneros: capa, casulla y dalmáticas, que el mismo cardenal había encargado en 1513 (aunque nunca lo utilizó pues se terminó en 1520, tras la muerte de Cisneros), en SÁNCHEZ GAMERO, J.P., Cisneros: arquetipo de virtudes, espejo de prelados, Cabildo Primado Catedral de Toledo 2017, p. 310. A su muerte el taller pudo quedar en manos de su hijo, que se llamaba Sebastián como su abuelo al que se refiere uno de los documentos transcritos por García Rey, en el que se indica que Alonso de Covarrubias, como albacea testamentario, se ocupó de su enterramiento, en GARCÍA REY, V., Arquitectura, 107..., p. 95. Conocemos al menos otros dos bordadores coetáneos del mismo apellido: en primer lugar, Alonso de Covarrubias, cofrade de la Cofradía del Ángel san Gabriel en Santa María la Blanca de Burgos (1511), en ARCHIVO DIOCESANO DE BURGOS [en adelante: ADB.], PSM Blanca, Leg. 16-53 y 54. Esta iglesia, muy próxima al castillo burgalés, fue antigua sinagoga, igual que la toledana con la misma advocación, sus parroquianos eran fundamentalmente conversos o cristianos nuevos. Y, mucho más célebre, Hernando de Covarrubias, bordador real, documentado entre 1489-a.17-diciembre-1507 en ARCHIVO GENERAL DE SIMANCAS, [en adelante AGS], R.G.S., leg.148906, doc. 58; ARCHIVO GENERAL DE LA CHANCILLERÍA DE VALLADOLID, [en adelante ARCHVA], Registro de ejecutorias, caja 222, doc. 29. Dentro de la Casa real ejercició asimismo el oficio de "bordador del Príncipe", en AGS. Casa y Sitios Reales, Leg. 11, fol. 4, cit. en VARIOS, Don Juan, Príncipe de las Españas (1478-1497): colección diplomática, 1999, p. 53. Ver también FOLIANA FERRÁNDEZ, N., "Ornamentos 
requería una formación artística que bien pudo inspirar la manera de hacer del joven Alonso, que inicialmente se formaría en el taller familiar, junto a su padre y hermano, lo que permite suponer que desde niño viviría en este ambiente artesanal.

Fueron su infancia y adolescencia un momento de esplendor artístico de Torrijos, donde al parecer vivía. Los señores de la Villa ${ }^{16}$ emprendieron

litúrgicos encargados por la reina Isabel la Católica a Covarrubias (1488), en Estudios sobre patrimonio, cultura y ciencias medievales [en adelante EPCLM], Granada, 2 (2016) 496. Nos preguntamos si el desconocimiento de los orígenes y ascendencia de Alonso de Covarrubias tenga que ver con su posible pertenencia a una familia conversa, pues tal hipótesis daría sentido a las incoherencias en los testimonios que figuran en el informe vinculado al expediente de limpieza de sangre de su hijo Antonio.

${ }^{16}$ Don Gutierre de Cárdenas y doña Teresa Enríquez compraron la villa de Torrijos al cabildo de la catedral de Toledo en el año 1482. Por entonces ya era señor de Maqueda y contaría con muchos más señoríos y títulos: Señor de Elche, Maestre de la Orden de Santiago, Comendador de León, Contador mayor de los Reyes, Alcaide de los reales alcázares de Carmona, la Mota, Medina del Campo. Chinchilla y Almería, otorgados por los Reyes Católicos por su fiel servicio. Don Gutierre fue uno de los personajes más influyentes de la Corte, desde que fuese designado como maestresala de la princesa Isabel. Había sido introducido por su tío don Gonzalo Chacón y por el arzobispo Carrillo, y siempre estuvo al lado de la princesa. Desde su posición, participó en la negociación de su matrimonio con el príncipe Fernando, y fue uno de los organizadores de la proclamación de Isabel en Segovia. Se convirtió en pieza esencial en la construcción de la monarquía e intervino de manera magistral en la Guerra de Granada a través de las negociaciones de la rendición de Málaga, asistiendo al cerco de Baza, o capitaneando la entrada a la ciudad de Granada y recibiendo las llaves de la Alhambra de manos del emir. Contrajo matrimonio en 1470 con doña Teresa Enríquez, que era hija de don Alonso Enríquez, Almirante Mayor de Castilla. Doña Teresa desde pequeña vivió con su abuela paterna, doña Teresa Quiñones, quien fue modelo de vida. Por esta vía, la paterna, era sobrina de doña Juana Enríquez, madre del rey Fernando el Católico y, por lo tanto, descendiente de los reyes castellanos. Se convirtió en una de las damas más leales y cercanas a la reina y junto a su esposo formó parte de la corte itinerante que acompañaba a los soberanos. Para conocer más sobre don Gutierre de Cárdenas: DE CASTRO, M., "El Comendador Mayor Gutierre de Cárdenas compra las villas de Torrijos y Alcabón", Anales Toledanos (Toledo), 34 (1997) 103-150; MADRID Y MEDINA, A. y MARÍN MADRID, P., "El caballero que recibió las llaves de la Alhambra: don Gutierre de Cárdenas, comendador mayor de León, Universidad abierta (Madrid), 28 (2009) 153-167; GARCÍA FENÁNDEZ, M., "Cárcel, horca y picota: la toma de posesión del señorío de Taha de Marchena por Gutierre de Cárdenas: estudio y edición", en Revista del Centro de Estudios Históricos de Granada y su Reino (Granada), 25 (2013) 289-311; MARTÍNEZ ESPAÑOL, G., "Donació, resistència i presa de possessió d'Elx i Crevillent a favor de Gutierre de Cárdenas", en La Rella: Anuari de L'Institut d'Estudis Comarcals del Baix Vinalopó, 30 (2017), pp. 117-148. En cuanto a doña Teresa Enríquez, la primera semblanza biográfica se realizó en fechas muy cercanas a su muerte, donde se presenta como modelo de viuda, en EIXIMENIS, F., Carro de las donas, Valladolid 1542. Más tarde se narraría su vida en estilo hagiográfico por ALARCÓN, M.A., Biografia compendiada de la Excelentísima Señora Doña Teresa de Enríquez llamada 'la loca del Sacramento', Valencia 1893. Estas inspirarán las siguientes biografias: OSABA, R., La loca del Sacramento o doña Teresa Enríquez, Ávila 192; BAYLE, C., La loca del Sacramento: Doña Teresa Enríquez, Madrid 1922. Estas obras serán referencia para las siguientes, APUNTES 
numerosas empresas artísticas que encomendarían a los más reconocidos arquitectos y escultores de la época. Es lógico pensar que allí instalara un taller Juan Guas ${ }^{17}$, maestro mayor de obras reales, y cabe la posibilidad de que fuese el director maestro de obras del monasterio de Santa María de Jesús ${ }^{18}$. También pudo tenerlo Antón Egas, que participaría en las obras del palacio de Altamira ${ }^{19} \mathrm{y}$, a partir de 1509, en las de la Colegiata del Santísimo Sacramento ${ }^{20}$, junto con su hermano Enrique. Santos Vaquero y Santos Martín afirman que Alonso de Covarrubias pudo intervenir en algunos de estos edificios ${ }^{21}$. Debió tener una especial vinculación con los señores de Torrijos e incluso cabe la posibilidad de que trabajase en otras obras que estos patrocinaron en Toledo ${ }^{22}$. En esta misma ciudad trabajó a las órdenes de Enrique y Antón Egas en el Hospital de santa Cruz ${ }^{23}$.

HISTÓRICOS sobre la "loca del Sacramento" y la villa de Torrijos, Toledo 1928. La más reciente es FERNÁNDEZ FERNÁNDEZ, A., Teresa Enríquez: la loca del Sacramento, Madrid 2001.

${ }^{17}$ En Torrijos vivían los Egas y también Juan Guas, que había casado con la torrijeña Marina Álvarez. Asimismo, fue cuna del imaginario Sebastián de Almonacid, en LONGOBARDO CARRILLO, J. y BUITRAGO MASELLI, J., La Colegiata de Torrijos, Diputación de Toledo, 1999, p. 16. Es posible que los padres de Alonso de Covarrubias llegaran atraídos por la demanda de trabajo tanto artístico como artesano en dicha villa.

${ }^{18}$ Edificado a imitación del Monasterio de San Juan de los Reyes de Toledo, en el que participaría este autor y posteriormente los Egas. Respecto al monasterio de Torrijos, Alarcón afirma que no se conoce el autor, atribuyéndose los planos a Juan Guas o a maese Rodrigo y Pedro Gumiel, en ALARCÓN, M.A., Apuntes históricos sobre la villa de Torrijos (Toledo) y sus más esclarecidos bienhechores, Valencia 1894, p. 207; IDEM, Biografía ..., p. 98.

${ }^{19}$ Este palacio de los duques de Maqueda, se ubicaba en la plaza principal de la villa. Su descripción en ALARCÓN, M.A., Apuntes históricos..., pp. 132-140. Longobardo afirma que fue demolido a principios del siglo XX, en LONGOBARDO CARRILLO, J., Alonso de Covarrubias..., p. 59. La portada se trasladó a principio del siglo XX a la finca de Alamín, en AZCÁRATE RISTORI, J.M., “Antón Egas”, en BSAA, 23 (1957) 13. Azcárate relaciona directamente a Antón Egas con las obras que se ejecutaban en Torrijos, en ibidem, p. 12.

${ }^{20}$ Como ya hemos señalado, la historiografía tradicional sitúa en esta construcción los comienzos artísticos de Covarrubias. Ubicada muy cerca del palacio de Altamira, se unía a él mediante un pasadizo elevado que fue destruido, por disposición testamentaria de doña Teresa, a su muerte, en LONGOBARDO CARRILLO, J., Alonso de Covarrubias..., p. 62. Su advocación al Santísimo Sacramento y sus orígenes están muy vinculados a la historia de la Cofradía del Santísimo Sacramento de San Lorenzo in Damaso, como veremos más adelante.

${ }^{21}$ SANTOS VAQUERO, A. y SANTOS MARTÍN, A., Alonso de Covarrubias..., p. 163.

${ }^{22}$ No sabemos qué maestros trabajaron en la Capilla de la Nuestra Señora de la Antigua de la Catedral de Toledo, pero no cabe descartar a los Egas. Según Gómez Moreno, Antón Egas sucedió a su padre como aparejador de la catedral de Toledo en el año 1495, "cuyas noticias no pasan de 1512 y cuyas obras desconocemos". Al año siguiente será su hermano Enrique quien sea nombrado Maestro Mayor de la Catedral, a la muerte de Guas, en AZCÁRATE RISTORI, J. M., “Antón Egas..., pp. 5-7. Esta capilla fue fundación de don Gutierre de Cárdenas, movido por doña Teresa para realizar una dádiva a favor de la Santa Iglesia Catedral, y el cabildo, agradecido, les concedió para ellos y sus sucesores dicha capilla, donde erigieron un pedestal dedicado a la Virgen coronado por dosel gótico, en ALARCÓN, M.A., Biografia ..., p. 111; IBIDEM; La villa de Torrijos..., p. 220-221. "Se trata de un recinto muy pequeño, que divide las dos bóvedas que dan frente a las capillas de la Pila Bautismal y la de doña Teresa de Haro. El retablo tallado en mármol, rematado en un dosel. Bajo este las figuras pintadas y estofadas. La principal es la 
Tras la muerte de Gutierre de Cárdenas, será su esposa, doña Teresa Enríquez, quien administre todo su legado y continúe las obras emprendidas ${ }^{24}$. Al respecto, será la encargada de cumplir las cláusulas testamentarias sobre sus enterramientos en el convento que habían promovido en Torrijos ${ }^{25}$. Cabe la posibilidad de que el joven Alonso trabajase en las esculturas funerarias ${ }^{26}$, pues como sabemos

imagen de la Virgen que titulan de la Antigua, pues parece ser que perteneció a la primitiva Iglesia antes de la mezquita, y que se encontró escondida. Flanqueada por las figuras de don Gutierre de Cárdenas y su esposa que ofrecen a su hijo e hija respectivamente. Debajo tres hornacinas góticas con tres tablas antiguas, del nacimiento de Cristo, de la imposición de la casulla a san Ildefonso y en medio san Gregorio diciendo misa. Fundación de una capilla por parte de don Gutierre con tres misas semanales", en PARRO, S.R., Toledo en la Mano, o descripción histórico-artística de la magnífica catedral y de los demás célebres monumentos, Toledo 1857, t. I, p. 513-515. Y ORTIZ, B., Descripción de el sumo y máximo templo de la Santa Iglesia de Toledo y de todas las demás cosas que en él hai dignas de sauerse por el doctor Blas Ortiz, Canónigo de la dicha santa iglesia, Toledo 1546, pp. 231-233. El dosel de estilo gótico guarda relación con las tablas del retablo, pero ni estas ni la verja tienen que ver con la imagen mucho más antigua, en MARTíNEZ VEGA, R., "La catedral de Toledo y la santísima Virgen", Toletum (Toledo), 54 (1933) 11-48.

${ }^{23}$ Martínez analiza el proceso constructivo de la escalera del claustro y llega a la conclusión de que se realizó en tres fases. El primer periodo tras la construcción del hospital por Enrique Egas, momento al que nos referimos, entre 1517-1524. Considera que, en este tiempo, Covarrubias pudo colaborar formándose como escultor en la construcción de una primera escalera claustral de tres tramos de la que se conservan los dos arcos escarzanos en que se encuadra la actual escalera, en MARTÍNEZ, J., "Nuevas aportaciones..., pp. 140-144.

${ }^{24} \mathrm{Al}$ poco de quedar viuda, la hambruna asoló los pueblos de Castilla. De manera generosa comenzó a repartir limosna entre los pobres y así lo hizo hasta su muerte. Muchos de los que acudían a la generosidad de doña Teresa llegaban en malas condiciones físicas e incluso enfermos, y los alojaba en su casa para su curación. Finalmente mando edificar un hospital al que dotó con camas, colchones y buenas rentas. Además, realizó otras obras pías: en Torrijos un monasterio de monjas de la Concepción (el segundo de la orden, después del que fundara en Toledo su amiga santa Beatriz de Silva), y otros dos en Maqueda (también de monjas de la Concepción) y Almería (monjas de la Trinidad), respectivamente. En EIXIMENIS, F., Carro..., pp. 30-31. En la Corte su piedad y vocación fundadora llegó a ser motivo de burla y chanza en la Crónica burlesca de don Francés de Zúñiga, en la que don Fadrique Enríquez, Almirante de Castilla, presenta a su hermana a Carlos $\mathrm{V}$ en los siguientes poco elogiosos términos: "Tengo una hermana, que es llamada doña Teresa Enríquez; saca cada año seys ánimas de Purgatorio y mete a su hijo, el Adelantado de Granada, y a doze nietos en el Ynfierno", en SÁNCHEZ PASO, J.A., Crónica burlesca del Emperador Carlos V, Universidad de Salamanca, Salamanca1989, p. 71.

${ }^{25}$ Fue destruido por un incendio durante la Guerra de la Independencia, y sus ruinas vendidas a vecinos de Torrijos tras las leyes desamortizadoras del año 1834. Los materiales aprovechables también se vendieron. En ALARCÓN, M.A., Biografia..., pp. 100-101. Los túmulos de los patronos, después de pasar unos años depositados en un almacén del hospital de la Trinidad, se ubicaron definitivamente en el centro del coro de la Colegiata del Santísimo Sacramento de Torrijos en los años 20 del siglo XX, en LÓPEZ TORRIJOS, R. y NICOLAU CASTRO, J., "La familia Cárdenas, Juan de Lugano y los encargos de la escultura genovesa en el siglo XVI", en BSAA (Valladolid) 68 (2002) 174.

${ }^{26}$ Como sabemos, su primera obra documentada fueron los sepulcros de los Rojas en la capilla mayor de la iglesia de san Andrés de Toledo, en el año 1513, y posteriormente los de los arcedianos en la catedral toledana, en SANTOS VAQUERO, A. y SANTOS MARTÍN, A., Alonso de Covarrubias..., p. 165. Por él consta que su oficio era el de imaginero, transcrito por 
sus primeras obras documentadas las ejecutó como imaginero ${ }^{27}$. En 1510 contrae matrimonio y, por lo tanto, adquiere una nueva vinculación de índole familiar con los $\operatorname{Egas}^{28}$, más allá de la laboral. García Rey sitúa el comienzo de la producción de Covarrubias en el año 1513, con el encargo de la sepultura para los padres de don Francisco de Rojas, en la capilla mayor de San Andrés. ${ }^{29}$. Un año antes había sido convocado para asistir a la Junta de Salamanca para la construcción de la Catedral nueva, invitado en calidad de imaginero ${ }^{30}$.

Después encaminará sus pasos hacia Guadalajara. Allí, como ya hemos señalado, realizará la obra en la que evidenciará por primera vez sus conocimientos del romano, además de ser su primer trabajo documentado como cantero y en solitario $^{31}$. Un importante aspecto para destacar, que ha llamado la atención de diversos autores, es la hornacina de la portada, en concreto la imagen. En sus formas se ha apuntado la posibilidad de que tomase como referencia la Piedad

GARCÍA REY, V., en Arquitectura, 107 (1928) 95. Trabajaba por entonces a las órdenes de los Egas, y de dicho contrato pudo derivar la amistad con Juan de Borgoña, tal como apunta GARCÍA REY, V., en Arquitectura, 97..., p. 170. Junto a este artista volvería a trabajar en la capilla de la Trinidad, la primera que ejecutó como arquitecto en la catedral de Toledo: "Covarrubias fue el arquitecto reedificador de la capilla, y a la vez el entallador y escultor del retablo, enterramiento y cuerpo arquitectónico; Borgoña, el autor de las diez y nueve tablas de pintura" en GARCÍA REY, V., Arquitectura, 105..., p. 4. Posiblemente ya era un joven escultor cuando se realizaron los sepulcros de don Gutierre y doña Teresa, en los que, a juicio de Azcárate, pudo participar, en AZCÁRATE RISTORI, J. M., "Antón Egas”..., p. 13. López Torrijos y Nicolau Castro lo sitúan cronológicamente entre 1498, año en que testó don Gutierre, y 1528, en que lo hizo su esposa. Aunque tampoco señalan el artífice, precisan que "estilísticamente el sepulcro y sus yacentes nos parecen relacionados con lo que se trabaja en Toledo, Ávila o Sigüenza en el primer tercio del siglo XVI. Las tumbas de Torrijos y el sepulcro de los Arce de Sigüenza tienen un mismo aire común, aunque estéticamente la balanza se incline hacia el lado de Guadalajara. Junto a las características dominantes claramente continuadoras del gótico de Toledo de fines del XV, hay en esta obra elementos claramente italianos en la decoración, pero en el estado actual de nuestros conocimientos no parece que podamos inclinarnos más hacia Italia, ya que los elementos que aquí aparecen ya eran sobradamente conocidos en España", en LÓPEZ TORRIJOS, R. y NICOLAU CASTRO, J., "La familia Cárdenas..., p. 76.

${ }^{27}$ Realizados en el año 1514, se trata de dos hornacinas adornadas con follaje gótico, en las cuales se insertan las estatuas yacentes de don Tello de Buendía, obispo de Córdoba y arcediano de Toledo, y de don Francisco Hernández de Cuenca, arcediano de Calatrava. En este período Covarrubias es contratado como entallador en la Catedral. En SANTOS VAQUERO, A. y SANTOS MARTÍN, A., Alonso de Covarrubias..., p. 165.

${ }^{28}$ Era hija de Miguel Sánchez y Margarita Gutiérrez Egas y posiblemente nieta de Anequín de Egas y, por lo tanto, sobrina de Enrique y Antón Egas, en GARCİA REY, V., Arquitectura, 97..., p. 169.

${ }^{29}$ GARCÍA REY, V., Arquitectura, 97..., p. 170. Azcárate señala como posible arquitecto o maestro mayor de la capilla a Antón Egas, en AZCÁRATE RISTORI, J. M., “Antón Egas..., p. 9.

${ }^{30}$ Ibídem, y AZCÁRATE RISTORI, J. M., “Antón Egas..., p. 13.

${ }^{31}$ La vasta producción artística de Alonso de Covarrubias imposibilita enumerar todas las obras que realizó, que dirigió o en las que colaboró. Remitimos a la bibliografía antes señalada, que proporciona una amplia información al respecto. 
vaticana de Miguel Ángel ${ }^{32}$, hasta tal punto que parece viable el conocimiento directo de la obra original del genio italiano.

Y lo cierto es que Alonso de Covarrubias viajó a Italia, en relación con la fundación, construcción y dotación, por doña Teresa Enríquez, de una capilla en la Iglesia de San Lorenzo in Damaso, en la ciudad de Roma ${ }^{33}$. Esta señora, muy devota del Santísimo Sacramento, tuvo noticias de que, en la Ciudad Eterna, desde el año 1501 existía una cofradía cuyo fin era llevar el Viático a los enfermos ${ }^{34}$. Era una cofradía muy humilde y, a su juicio, no realizaba el traslado con el decoro que se requería. Así, aprovechó el viaje que fray Antonio de Jaén realizó a la Urbe, para asistir al Capítulo General de la Orden de san Francisco, para encomendarle que entregase a la cofradía un baldaquino de

${ }^{32}$ SANTOS VAQUERO, A. y SANTOS MARTÍN, A., Alonso de Covarrubias..., p. 130.

33 "La Basílica de san Lorenzo fue erigida, en 370 para guardar las reliquias del esclarecido mártir (san Lorenzo), y poco después en 384 ya encerraba también los despojos mortales del santo Pontífice (Dámaso I), que le da el segundo nombre. Restaurada en tiempos de Adriano I y de León III, fue casi reedificada a finales del siglo XV, en el pontificado del papa español Alejandro VI: los vicecancilleres han mostrado siempre su devoción y su munificencia en conservar y enriquecer a porfía la Basílica de que son titulares: la fábrica en su interior es un recinto cuadrado dividido en tres naves, cuyas capillas ofrecen riqueza de mármoles, de pinturas al fresco y de monumentos. Cuando Ignacio de Loyola y sus compañeros comenzaron en Roma las tareas apostólicas, que forman la base de su instituto, a Francisco Xavier fue señalada la iglesia de san Lorenzo in Damaso para la predicación que ejerció con asombro de sabios y edificación del pueblo, hasta su partida para la conquista espiritual de las Indias. En la misma iglesia de san Lorenzo, a principios del siglo XVI, una noble dama española, Teresa Enríquez, erigía y dotaba espléndidamente la confraternidad del Santísimo Sacramento, que tiene su capilla en la nave de la izquierda. Bernini hizo el altar mayor, y Federico Zuccheri el dibujo del gran cuadro. La capilla, donde se venera la imagen antiquísima, bizantina de la virgen, que estuvo en santa María de Grotta Pinta, es de arquitectura de Cortona, y de su mano la pintura al fresco de la bóveda", en CATALINA Y DEL AMO, S., Roma: obra póstuma por Francisco Cutanda, M. Rivadeneyra, Madrid 1873, pp. 590-591.

${ }^{34}$ Sobre los inicios: "nell'anno mill e cinquecento e uno, nel Pontificato d'Alisandro Sesto. Un devoto sacerdote mosso da divino Spirito (parengogli tal cosa mal fatta) si concordò con quattro secolari, quali trovò dell' istessa opinione sua, e insieme domandorno, e ottennero dal Reverendo Capitolo e Canonici della Chiesa Collegiata di S. Lorenzo in Damaso, quel luogo d'essa Chiesa, che è a man sinistra, dell'entrare della Porta maggiore, et due al presente si vede l'ornata cappella del detto miracolosissimo Sacramento, che in quei tempi doueua esser voto et senza alcun ornamento et quello accomodarono et ornarono à por spese, facendoui collocare il medesimo gloriosissimo Sacramento molto honoratamente", en FANUCCI, C., Trattato di tutte l'opere pie dell'alma cita di Roma, Roma 1601, pp. 233 en https://archive.org/ details/trattatodituttel00fanu (consultado: 24-05-2021). Al respecto el padre Rufino Osaba dice que un hijo de san Francisco llamado Querubín de Espoleto, había fundado en Roma Escuelas y Compañías del Santísimo Sacramento para acompañar al Viatico y fomentar el culto Eucarístico. La señora de Torrijos envió en 1505 limosna y alhajas a dicha Compañía, por medio del padre provincial de san Francisco en Castilla, fray Antonio de Jaén. Más tarde fundó la Cofradía Sacramental de san Lorenzo in Damaso y la de Torrijos; en OSABA, R., La loca del Sacramento..., p. 33. 
brocado de oro, forrado de damasco blanco, así como cierta cantidad de ducados para dotar dicha cofradía ${ }^{35}$.

Ya en Roma, fray Antonio de Jaén insistió en que uno de los cofrades informase personalmente a doña Teresa en Torrijos. Así la señora recibió al representante de la Hermandad y luego "despachó al embajador con un capellán suyo llamado Covarrubias y carta para la cofradía". Además, envió dos acémilas cargadas de ornamentos preciosos para el altar y una considerable suma de dinero para que hiciese obra en la capilla, en mármol y bronce dorado, prometiendo asimismo por medio del capellán mejores dádivas para aumento del culto del Santísimo Sacramento y adorno de la capilla colocando el retablo de la Última $\mathrm{Cena}^{36}$. Dice Alarcón que en 1508 se erigió "una suntuosa capilla de mármoles y de bronces dorados a la derecha del altar mayor de la iglesia de San Lorenzo in Damaso, colegial de canónigos de la ciudad santa" y que doña Teresa la dotó de mucha renta y ornamentos, tanto para que el Sacramento Eucarístico se administrase con el debido culto a los enfermos, como para su exposición. Como testimonio de lo cual se erigió una lápida conmemorativa ${ }^{37}$.

${ }^{35}$ BAYLE, C., La loca del Sacramento..., p. 315. Se entregó en presencia de cofrades de la dicha Hermandad o asociación, y para sus cofrades. Se entregó dicho baldaquino, 25 ducados de oro en oro de cámara en dinero contante para la conservación del dicho baldaquino; así mismo para comprar algunos censos y otras cosas convenientes a la dicha Hermandad, otros 100 ducados de oro en oro de cámara. Además de un tabernáculo de plata dorada para llevar al Santísimo Cuerpo de Cristo, de valor de 60 ducados. Prometieron llevarlo bajo el baldaquino y cuatro teas de cera blanca encendidos llevados por cuatro cofrades; BAYLE, C., La loca del Sacramento..., pp. 316-318. "Vanno vestiti di sacchi bianchi, portando per insegna le cinque piaghe del Nostro Signore Gesù Christo con la Corona di spine sopra. In tutte le feste et apparati che fanno sempre pongano l'armi di detta Signora Teresa, che sono dentro à uno scudo tre Torri, opero Rocche, come si pongo ancora vedere sopra le porti della Cappella predetta" en FANUCCI, C., Trattato di tutte..., p. 240.

${ }^{36}$ BAYLE, C., La loca del Sacramento..., pp. 204 y 205. Al respecto: "Doppo molti dì lo rimandò accompagnato da vn suo capellino chiamato Couaruuias et due altri compagni, con due muli carichi di paramenti d'Altare, come sono Pianate, Piuiali, Paliotti, Capisci, Corporali et altre cose simili fino alla Purificatori, con grossa quantità di denari, con li quali fù fatto fabricarle quel bello et gran Tabernacolo indorato, quali si vede el presente sopra l'Altare di detta Cappella. Ancora ne fù dipenta essa Cappella con oro et altri ornamenti molto vistosi et serata con conci. Di marmo bianco messo à oro et balausti di bronzo, come fin'hora oga'vno la può vedere" en FANUCCI, C., Trattato di tutte..., pp. 238.

${ }^{37}$ En ALARCÓN, M. A., Biografia ..., pp. 47-49. Según Fanucci "I fratelli della Confraternità di Roma, per mostrarsi in qualche cosa grati verso la suddetta Signora di tanti beneficij da lei ricevuti, oltre all'Orationi et preci che hanno fatte et fanno per lei, gli hanno (in vna pietra di marmo posta nel muro dentro alla Cappella, verso il Corno destro dell' Altare) fatta intagliare questa seguente inscrittione: D. O. M./ Illustris genere, synceraq. fide, ac vera pieta/te illustrior Teresia Enriques, Catholicae Hi/spaniae clarum decus cui paternum et iguale/ stemma religiosum et refulget: Hoc sacellum/ honori Sacratissimae Eucharistiae, cuius ardore/ flagrat religiosum pectus ornauit, instruxit, / ac dotauit. Anno Salutis M D V III" en FANUCCI, C., Trattato di tutte...., pp. 238-239. 
Como hemos indicado en anteriores líneas, envió a un capellán suyo llamado Covarrubias. Se trataba de Juan de Covarrubias, hermano de Alonso ${ }^{38}$, donde llegaría con el cometido de hacerse cargo de las obras. En el seguimiento de dichas obras, Alonso de Covarrubias dejaría constancia de su visita en Roma como testigo, en calidad de imaginero, dos años antes de iniciarse la construcción de la Colegiata de Torrijos ${ }^{39}$. El oficio de imaginero con el que figura ya en tan tempranas fechas invita a pensar que se inició en la profesión antes de la fecha que venía proponiendo tradicionalmente la historiografía.

Si tomamos como referencia las fechas de nacimiento unánimemente admitidas por nuestra historiografía contaría con aproximadamente 19 años durante su estancia en Roma. Debemos tener en cuenta que se considera que en aquellos momentos estaría trabajando por cuenta ajena y este sería el motivo por el que, aunque pudo volver con nuevos conocimientos a la romana, no los pondría en práctica hasta asumir encargos propios en que así lo pidiese el cliente. Esto debió ocurrir en 1526, con la ejecución de la Iglesia de la Piedad de Guadalajara para doña Mencía de Mendoza donde muestra un avance estilístico que también se denota en la bóveda de cañón de la capilla que realizó en la Catedral de Sigüenza ${ }^{40}$.

${ }^{38}$ Juan de Covarrubias fue racionero de la Catedral de Salamanca desde 1516 hasta 1559 aproximadamente. Florencio Marcos le documenta citado por primera vez en las Actas Capitulares del cabildo catedralicio de Salamanca de, 21 de abril de 1516, con motivo del remate de unas casas en San Isidro, y la última el 5 de mayo de 1559, en la que "se hizo el primer cabildo de las casas en las que murió". En Salamanca crió y educó a Diego de Covarrubias y Leyva y Antonio de Covarrubias y Leyva, hijos de Alonso de Covarrubias; y a Sebastián Covarrubias y Orozco, sobrino de ambos. Fue enterrado en la catedral de Salamanca; en MARCOS RODRÍGUEZ, F., "Don Diego de Cobarrubias y la Universidad de Salamanca", Salmanticensis (Salamanca), 6 (1959) 39. Cabe destacar la importancia de estos tres personajes: Diego de Covarrubias fue jurista, catedrático de Derecho Canónico en la Universidad de Salamanca, oidor en la Real Chancillería de Granada, obispo de Segovia y Ciudad Rodrigo, teólogo en el Concilio de Trento, presidente del Real Consejo de Castilla, maestro de la Escuela de Salamanca y clave para la configuración de la Monarquía hispánica en el reinado de Felipe II. Antonio de Covarrubias y Leyva, también jurista, acompañó a su hermano en las Sesiones del Concilio de Trento, fue oidor, consejero real y maestrescuela de la Santa Iglesia Catedral de Toledo. Amigo de Doménikos Theotokópoulos (hizo retrato de ambos hermanos). El tercero, reputado autor del Tesoro de la lengua castellana o española, publicado en 1611, fue nieto de Marcos de Covarrubias, hermano de Alonso y de Juan. Fue canónigo en la catedral de Cuenca, oficio que le cedió su tío abuelo Juan de Covarrubias. Datos biográficos tomados del Diccionario biográfico de la Real Academia de la Historia, en http://dbe.rah.es/ (consultado 23-05-2021).

${ }^{39} \mathrm{La}$ Colegiata de Torrijos; se comenzó a erigir en torno a 1509, como se ha indicado en líneas anteriores. Teresa Enríquez obtuvo licencia para hermanar las Cofradías del Santísimo Sacramento de San Lorenzo in Damaso y de Torrijos, tanto en lo temporal como en lo espiritual. Además, fue precursora de las Marías, con licencia para que los capellanes de la Iglesia Sacramental de Torrijos visitasen todos los Sagrarios de España y Portugal. También para fundar Cofradías en ambos reinos, subordinadas a la de Torrijos; ALARCÓN, M. A., Apuntes históricos sobre la villa de Torrijos (Toledo) y sus más esclarecidos bienhechores, Valencia 1894, pp. 213-214.

${ }^{40}$ SANTOS VAQUERO, A. y SANTOS MARTÍN, A., Alonso de Covarrubias..., pp. 125 y 137. 
En cuanto a su vinculación con doña Teresa Enríquez, y con la familia Cárdenas, esta debió ser muy estrecha, tal como indica que en el año 1562 actuase como fiador, por una cuantía de 2.000 ducados, de doña Ángela de Cárdenas y Velasco, hija de los duques de Maqueda, como parte de la dote de sus desposorios con el primogénito del duque de Segorbe ${ }^{41}$.

\section{TESTIMONIO NOTARIAL DE LAS OBRAS DE SAN LORENZO IN DAMASO ${ }^{42}$}

Se trata de un interesantísimo legajo que, además de documentar la presencia de Alonso de Covarrubias en Roma, contiene relevante información respecto a los artistas que trabajaron en la Capilla del Santísimo Sacramento de San Lorenzo in Damaso, a principios del siglo $\mathrm{XVI}^{43}$. A continuación, enumeramos de manera cronológica las principales cuestiones que refiere:

Durante el año 1507, Rodrigo de Salinas, presbítero de la diócesis de Segovia ${ }^{44}$, merced a un poder otorgado por doña Teresa Enríquez ante el notario público de Toledo Alfonso Díaz ${ }^{45}$, realizó en Roma diversas gestiones en pro de la Venerable Sociedad del Cuerpo de Nuestro Señor Jesucristo, con advocación en la iglesia de San Lorenzo in Damaso, en el rione Parione, en Roma ${ }^{46}$, para cuya capilla

\footnotetext{
${ }^{41}$ Citado en SANTOS VAQUERO, A. y SANTOS MARTíN, A., o. c., p. 112.

${ }^{42}$ Es un libro en pergamino, encuadernado en cuero, de 22 folios en latín. Está compuesto por varias unidades documentales y fechado en Roma, en una horquilla que comprende desde el 8 de enero de 1507 hasta el 15 de agosto de 1509. Su título completo es Testimonio notarial de las obras de una capilla en la iglesia de San Laurencio in Damaso de Roma, dedicada al Cuerpo de Nuestro Señor Jesucristo, costeada por Teresa Enríquez [Alvarado, señora de Torrijos], esposa de Gutierre de Cárdenas, [VII señor de Maqueda] y fundador del mayorazgo de Maqueda. Se encuentra custodiado en el Archivo Histórico de la Nobleza [en adelante AHNOB], con signatura BAENA, C.200, D.8.

${ }^{43}$ Sería interesante adjuntar la transcripción y traducción de dicho documento, pero excede el propósito del presente artículo. Por ese motivo se ha optado por enumerar brevemente las cuestiones que trata como se verá a continuación.

${ }^{44}$ Aunque la mayor parte de los documentos se refieren a él como "venerabili viro domino Roderico de Salinis, clerico Segobien. diocesis, procuratori et procuratorio nomine nobilis e jllustris domine Theresie Henrechez, jspane, relicte quondam nobilis domini Gutterij Cárdenas", en ocasiones sustituyen "clerico" por "presbiter".

${ }^{45}$ Además de no transcribirse el contenido ni indicar la fecha del del mandato de procuración, la referencia al notario público oscila entre "discretum virum domini Alfonsum Díaz, laicum Toletan. diocesis", "discreti viri domini Alfonsi Díaz, Toletan. diocesis, notarij publici" y "discreti virj dominj Alfonsi Díaz, clerici Toletan. diocs., notarij publici".

46 "Venerabili Societati Corporis Domini nostri Jesucristi, que est in dicta ecclesia Sanctj Laurentij in Damaso de Vrbe". La Bula de Julio II, despachada en Roma el 21 de agosto de 1508 otorgó licencia para fundar una capilla principal, capellanías y la Cofradía del Santísimo Sacramento; en ALARCÓN, M.A., Apuntes históricos..., p. 213. Dice el padre Osaba que por
} 
comisionó una serie de obras. En primer lugar, el 8 de enero encarga a los «honorabiles viri magistri Antonius Michaelis de Sino et Bartholomeus Franciscj de Rubeis, laici fesulani [Fiésole], scultores marmorum in Vrbe», la ejecución de un parapeto ${ }^{47}$ así como la hechura de un tabernáculo con «magister Bartholus Francisci, de Florentia, in Vrbe comorans ${ }^{48}$.

El 24 de enero de 1507, la cofradía obtuvo permiso del cabildo y canónigos de San Lorenzo in Damaso para erigir una capilla y una sepultura para sus cofrades ${ }^{49}$.

dicha bula constituyó a Teresa Enriquez como fundadora de las Cofradías del Santísimo, en OSABA, R., La loca del Sacramento..., p. 39. Además, los patronos contaban con licencia para formas estatutos, con facilidad de añadir, quitar y alterar en ellos, ALARCÓN, M.A., Apuntes históricos..., p. 215.

${ }^{47}$ Una balaustrada, ante el altar de la capilla que debían realizar en dos meses, por la suma de 200 ducados, de los que reciben 50 como primera paga. VALTIERI, S., La Basilica di $S$. Lorenzo in Damaso..., p. 60 indica que "l'8 gennaio 1507 si commissiona la balaustrata per 200 ducati agli scultori romani Antonio Michele de Sino e Bartolomeo Francesco de Rossi".

${ }^{48}$ Debía ejecutarse antes de marzo por un importe de 55 ducados, entregándole un tercio como primera paga: "honorabilis vir magister Bartholus Francisci, de Florentia, in Vrbe comorans $[\ldots]$ promisit et conuenit [...] facere construere et laborare vnum tabernaculum ligneum pro Corpore Sacratissimj Domini nostri Jesuchristi vbi de lignis albucij et tilie bonis [...] tabernaculum facere et laborare [...] promisitque [...] dictum tabernaculum penere et collocare in loco vbi ponj et collocari debet" ("Rome, in Regione Parionis, in bancho spectabilis viri domino Victorij Zelonis, mercatoris Florentinus, Roman. Curiam sequen.”, 8-enero-1507, ante Ascanio Marso; fols. 3r-4r), actuando como fiador del artista "honorabilis vir magister Jacobus Antonij, mercator lignorum, in Vrbe stiens.". Dice Valtieri que "I contratti stipulati con vari artisti vanno dal 1507 al 1509: [...] il 18 gennaio 1507 un tabernacolo in legno "arbuccio" per 55 ducati a Bartolomeo di Franceso da Firenze (che i pittori romani Pellegrino e Girolamo si impegneranno a decorare con stucchi minuti per 30 ducati l' 11 agosto 1509); allo stesso artista il 26 aprile sono commisionate per 22 ducati le due porte ai lati dell'altare in legno "arbuccio" foderato con tavole di noce e con fregi come da disegni forniti". Añade, en la nota 2, que "Deve trattarsi del tabernacolo disegnato tra la fine del XV e gli inizi del XVI secolo", cita E. BENTIVOGLIO, "Nel cantiere del palazzo del card. Raffaele Riario (La Cancelleria). Organizzazione, materiali, maestranze, personaggi", Quaderni dell'Istituto di Storia dell'architettura 169-174 (1982) 27-34, en VALTIERI, S., La Basilica di S. Lorenzo in Damaso..., p. 60,

49 "guardianj et confratres venerabilis Societatis Corporis Domini nostri Jesucristi, que ad presens in ecclesia Sancti Laurentij in Damaso de Vrbe existit deuotionis feruore cupiant et affertent habere vnum locum proprium in dicta ecclesia in quo possint construere seu construi facere vnam capellam cum altari ac illam et illud ad augmentum Diuun cultus et Corporis Domini nostri Jesuchristi decenter exornare et postquam dictam capellam siue altare eraxerint/ eruxerint? et ornauerint [...] vellent dare et concedere locum vbi nunc est altare dicte societatis in dicta ecclesia vbi sub fornice dicte ecclesie ipsa societatis jntendit ibi construere seu construj facere vnam capellam cum altari in honorem Corporis Dominj nostri Jesuchristi et illam condecenter ornare tam in sctructuris quam etiam paramentis adeo quod erit non solum ad decorem omnipotentis Dei sed etiam totius ecclesie predicte [...] dederunt et concesserunt locum predictum sub fornice dicte ecclesie vbi nunc est altare Corporis Christi dicte societatis pro agumento et honore diuinj cultus [...] edificare capellam et altare [...] sanctum cultum diuinum uel capellam siue sepulcrum in eo construendum" (“Actum Rome, in sacristia Sancti Laurentij”, 24-enero-1507, ante Ascanio Marso; fols. 1r-1v). Recogido en VALTIERI, S., La Basilica di S. Lorenzo in Damaso..., pp. 59-60. 
El 27 de enero de 1507, Rodrigo de Salinas contrata con el «honorabilis vir dominus Thomas Gerardi de Pisis» la ejecución de 50 balaustres de metal antes del Domingo de Ramos ${ }^{50}$.

Además de contener información sobre dichas obras, también refiere la adquisición de casas ${ }^{51}$. Así, el 7 de marzo Rodrigo de Salinas adquiere, en nombre de doña Teresa Enríquez y de sus herederos y sucesores, las casas en el rione Ponte del ciudadano romano Andreas Opicionis de Pinciaronibus, habitante en el rione Sant'Angelo ${ }^{52}$, por 800 ducados, que el vendedor reconoce haber recibido $^{53}$. El miércoles, 19 de mayo, fray Miguel de Torrijos adquiere, en nombre

La concesión se hace en presencia y con el beneplácito del "rreuerendissimi in Christo pris. et dni. dni. Raphaelis Riarij, miseratione diuina Epi. Alban., Cardinalis Sancti Georgij Sancte Romane ecclesie, camerarii ac dicte ecclie. Sancti Laurentij in Damaso perpetuj comendatarij, in dicta ecclesia vicario generali" y destaca también la presencia, entre los canónigos del "priore, canonico et fabricatore Petro Marso". VALTIERI, S., La Basilica di S. Lorenzo in Damaso..., pp. 59-60 indica que "Il documento di concessione è pubblicato integralmente da E. BENTIVOGLIO, La cappella del SS. Sacramento in S. Lorenzo in Damaso [: "tantisque ornamentis fulgens"], in Colloqui del Sodalizio, 7, 1984, pp. 223-231.

${ }^{50}$ Por precio de 32 ducados que declara haber recibido: "promisit et conuenit facere et fabricare quinquaginta balagusta vel circa de metallo librarum vigintiduarum pro quolibet balagusto vel circa ex optimo metallo pulchra et polita hinc et vsque ad Dominicam Palmarum proxime futuram ["Hec Rome, in bancho nobilis virj dnj. Victorij Zelonis, mercatoris florentinus, Roman. Curiam sequen. in Regione Parionis, in platea Sanctj Laurantij in Damaso"], 25-enero-1507, ante Ascanio Marso; fols. 7r-7v). Actúa como fiador de dicho maestro "honorabilis vir dominus Bartholomeus Graffolinus, mercator Pisanus". Entre los testigos, destaca la presencia de Sancho de Villena ("prouido viro domino Sanctio de Viglena, canp.? procure.?").

${ }^{51}$ Doña Teresa Enríquez había comprado para la cofradía, en el año 1505, la mitad de una casa ubicada en la región del Ruence, en la misma ciudad de Roma, a la espalda de la Basílica de San Pedro y del hospital de Salvador, en AHNOB, BAENA, C.4.44. El Padre Osaba señala que Teresa Enríquez compró dos casas cuyas rentas pagaban la cera del alumbrado del altar y las procesiones, en OSABA, R., La loca del Sacramento..., p. 35

52 "dominus Andreas Obicionis de Piceronibus" / "nobilis vir dominus Andreas Opicionis de Pinciaronibus, ciuis Roman., de Regione Sanctj Angelj"/ "Andree Obicionis de Puntiaronibus?, ciuis [cives] Romanj, de regione Sancti Angeli" (Roma, 7-mayo-1507, ante "nobilis viri domini Jeronimj de Ricijs, ciuis Roman., et Ascanij Marsij, clerici Marsican. diocesis, notariorum publicorum"; fols. 4r-6r). Incluye la posterior posesión dada a Salinas de la casa y de sus miembros, derechos y pertenencias, con la entrega de las llaves, la entrada en la casa, caminar por ella y demás actos posesiorios habituales, en presencia de "magistro Angello dello Schiauo, jnquilino dicte domus" y demás testigos (fols. $6 \mathrm{v}-7 \mathrm{r}$ ),

53 "terrineam, solaratam et tugulatam, alte et basse, ab infimo vsque ad culmen... dictam domun iuxta domum basilice Sancti Petri de Vrbe quam de presenti inhabitat magister Laurentius de Villa, sutor, sitam in Regione Pontis, infra hos fines vbi cui: ab vno latere et retro sunt res dicte basilice Sanctj Petrj et Hospitalis Saluatoris ad Sancta Sanctorum, etiam de Vrbe, et Franciscus (-i?) de Caluis, juncte proindiuiso inter prenominatas, ab alio est domus dicte Basilice Sancti Petri, ante vero est via publica". Son fiadores del vendedor los "nobiles viri domini Marcus Opicionis de Piceronibus, de Regione Campi Martis, et Baptista quend./quond. Jacobi Cole Blasij, de Regione Columne, ciues Romani" ("Actum Rome in Regione Parionis, in bancho nobilis viri dominj Victorij Zelonis, mercatoris Florentinj, Romanam Curiam sequentis”). 
de doña Teresa Enríquez y de sus herederos y sucesores ${ }^{54}$, las casas que poseen en el rione Parione Rentius de Panibus y Paulo, su hijo, ciudadanos romanos, moradores en el mismo lugar ${ }^{55}$. Además, Rodrigo de Salinas, a causa de la gran devoción que doña Teresa Enríquez y su marido Gutierre de Cárdenas profesaban a la cofradía, el 4 de junio de 1507 le dona las casas, en misma zona, que adquirió en su nombre, para aumento del culto divino, en honor del Cuerpo de Nuestro Señor Jesucristo y en remisión de sus pecados, para que la cofradía distribuía perpetuamente sus frutos en honor y ornamento del Cuerpo de Nuestro Señor Jesucristo, mantenimiento de los ornamentos necesarios y salario de los capellanes que la cofradía establezca u otros usos píos similares ${ }^{56}$. Tres días más tarde, 7 de junio, fray Miguel de Torrijos, dona a tal fin las casas que adquirió en nombre de doña Teresa Enríquez ${ }^{57}$.

Consta asimismo por el documento anterior la donación de un cáliz de plata dorado y un misal ${ }^{58}$. Además, el 26 de abril, el "honorabilis vir magister Bartholomeus Francisci, de Florentia, carpentarius in Vrbe" se compromete con Rodrigo de Salinas a labrar dos puertas de madera ${ }^{59}$.

54 "venerabilis et rreligiosus vir frater Michael(is) de Turrillos, ordinis (en blanco) [sic, por Sancti Francisci], procur. et procurio. nomine jllustris domine Theresie",

${ }^{55}$ Que confirma doña Jerónima, mujer y madre de los vendedores, por precio de 600 ducados, de los cuales entrega 400: "nobilis vir dominus Rentius de Panibus et Paulus, eius filius, ciues Romani, de Regione Pontis, cum consensu et voluntate domine Jeronime, eiusdem Rentij vxoris [...] Rentij domum terrineam, solaratam et tegulatam sitam in Vrbe, in Regione Parionis, infra hos fines vbi cuj: ab vno latere sunt res Richardi de Mazatostis, ab alijs vero lateribus sunt res Christophori Antonij, de Regione Columne, retro et ante sunt vie publice". Es fiador del vendedor "nobilis vir dominus Stephanus da Fratellis, ciuis rromanus, de Regione Columne" ("Acta fuerunt hec Rome, in Regione Parionis, in domo habitationis dictj dni. Victorij Zelonis", 19mayo-1507; fols. 10r-11v). La mujer confirma la venta el mismo día, en casa de los vendedores ("nobilis domina Jeronima, vxor dominj Rencij de Panibus, de Regione Pontis [...]. Acta fuerunt hec Rome, in Regione Pontis, in domo habitationis dicti dnj. Rencij"; fols. 12r-12v).

56 "magnifica et jllustris domina Theresia relicta quomd. nobilis dominj Gutterrij de Cárdenas, magnum gerat deuotionis affectum erga societatum Corporis Domini nostri Jesucristi que este in collegiata ecclesia sanctj Laurentij in Damaso de Vrbe et propterea ipsa domina Theresia studeat prefatis congregationibus siue societabibus manus porrigere adintritos? et de sua propria sustancia illis pro diuinj cultus augmento et honore prefati Corporis Domini Nostri Jesuchristi ac pro pecatorum suorum remissione aliquid elargiri et sibi celestem thesaurum quantum cum Dei aduitorio potest vbi tinea et erugo non demolitur comparere, en "Rome, in Regione Parionis, in domo dominj Victorij Zelonis, mercatoris florentinus", 4-junio-1507, ante Ascanio Marso; fols. 8v-9r.

57 "Rome, in Regione Parionis, in domo magistri Alexandri de Bononia"; 7-junio-1507, ante Ascanio Marso; fols. 12v-13.

58 "Jtem simili donationis titulo donauit, dedit, cessit et concessit eidem societati vnum calicem argenteum jnaratum, valoris viginti vnius ducatorum de carlenis, et vnum missale, valoris vnius ducatorum auri in auro", en "Rome, in Regione Parionis, in domo dnj. Victorij Zelonis, mercatoris florentinus", 4-junio-1507, ante Ascanio Marso; fols. 8v-9v).

${ }^{59}$ Por precio de 22 ducados, de los que reconoce haber recibido 10 , en un plazo de 30 días a contar desde el día siguiente. "promisit et conuenit, recipiendi et acceptanti fabricare in 
Ya durante el año 1508, el 4 de agosto, el venerable clérigo toledano Juan de Covarrubias ${ }^{60}$, capellán de la ilustre señora doña Teresa Enríquez, señora de Torrijos, acuerda con los "honorabiles viros magistros Johannempaulum et Siluestrem quondam Francisci Falange, pictores rromanos, presentes", la decoración pictórica de la capilla cuya ubicación próxima a la Capilla de la Concepción se precisa ${ }^{61}$, obligándose como fiador de los pintores Mario de Bucabellis, canónigo de dicha iglesia, y como fiador de Covarrubias el maestro Bernardino de Vercellis, cofrade de la cofradía ${ }^{62}$. Encierra máximo interés su

capella duas portas vbi fustan ex tabulis albucij et ab extra ab vtraque parte vbi foris et jntus ex tabulis nutis cum vno frisio tersit circumcirca et certis balagustis, secundum exigentiam operis dictarum portarum, secundum designum quod dictus magister Bartholus dedit eidem domino Roderico" (San Lorenzo in Damaso, 26-abril-1507, ante Ascanio Marzo; fols. 8r-8v). Entre los testigos, destaca la presencia de Juan Luis, clérigo hispalense ("Johanne Ludouici, clerico Ispalen. diocesis").

60 "Venerabili viro domino Johanni Couarrubies, clerico Toletan. diocesis, capellano jllustris dne. Theresie Anriachez, dne. de Torrigios, [hispane], presenti".

${ }^{61}$ Para saber más sobre la Cofradía de la Concepción, erigida en su capilla de San Lorenzo in Damaso por el cardenal Raffaele Riario, veáse BARONE, R. (ed.), La confraternita della SS. Concezione di San Lorenzo in Damaso di Roma (con l'edizione degli statuti del 1494), Archivio della Socità Romana di Storia Patria, 126 (2003) 69-135.

62 Durante dicho año, por precio de 230 ducados, distribuidos en cuatro pagas tres conforme se va ejecutando la obra de 60 ducados y el resto al final "[Al margen] «Contrato de pintar toda la capilla principal a toda costa por 230 ducados» [...] ad depingendum capellam Sacratissimj Corporis Domini Nostri Ihesuchristi sitam in ecclesia Sancti Laurentij in Damaso de Vrbe, modo et forma jnfrascriptis videlit quod dicti pictores [...] depingant quatuor arcus dicte capelle, duos videlit quj sunt jntus in capella et duos alios ab extra, super parapetto maiores, conformes cum pilastris de lapide tiburtino vbi conuingitur parapettum predictum hoc est a parte anteriori ab alia versus capellam Conceptionis vsque ad campanellum videlit cornices circuncirca in tota capella de auro fino et pulcerrime laboratum et jntus in dictis cornicibus vsque ad campitella etiam de auro fino et omnes campos de colore azurro fino cum folijs siue foliagijs etiam de auro puro et fino capita pilastrorum tota de auro ab jnteriori parte secundum quod pilastra se extendunt et super dictis capitellis in lapide tiburtino a parte exteriori depingant duos arcus, vnum in vna parte et alterum in alio, de stucco ad medium releuum cornices dictorum arcum de stucco vnam ab vna parte et alteram in alia cum auro puro et a parte anteriori dictarum cornicum cum certis rosis et folijs de auro cum suis quadris et predicta omnia de stucco deaurato campum de azurro fino et jntus dicti arcus in testudine dicte capelle debet fieri vnum opus de stucco, conforme vnum designo jam dato per dictos magistros depictores, et omnia ista cum suis cornicibus de stucco deaurato cum campis de auro esse debent et omnes campi planj erunt cum folijs de auro et campj de azurro et in octo campis magnis quatuor Euangeliste et quatuor Doctores Ecclesie pulcherrime depicti. Item medietas campi vbi erunt figure medietas a parte superioris de auro vermiculato vulgariter nuncupato musayco contrafacto a parte uero jnferiori laboratum de colore fino et in medio testudinis vnum festonum cum vno scuto jntus de medio releuo cum quinque Plagis Domini nostri Ihesuchristi et in alijs campis rotundis paruis cum scutis cum quinque Plagis predictis et in arcu super altare sit vnum paniglorium/pamglocium? de auro ad jnstar/justar brochati sumptuosum et a parte anteriori duo angeli volantes quj aperiant dictum paniglorium/pamglonum? sunt tres angeli ab utriaque parte uel plures si opus erit cum jnsignibus Passionis et in certis planis extra arcum muri prope altare cum certis frisis et tropheis ecclesiasticis 
data, pues recoge el precioso registro de la presencia en Roma en tan temprana fecha de un hermano del capellán de doña Teresa, el entallador Alfonso de Covarrubias:

"Acta fuerunt hec Rome, in dicta ecclesia Sancti Laurentij in Damaso, in capella predicta, presentibus ibidem venerabili uiro domino Georgio de Torres, familiari rreuerendisimij dominj cardinalis Sancti Georgij, et Domenico de Bosellis, seruiente armorum sanctissimj dominj nostri pape, et Alfonso de Couarrubies, scultor, hispano, testibus ad premissa vocatis specialiter atque rogatis".

La presencia del posteriormente famoso arquitecto toledano estaría así vinculada a la supervisión de las obras de la capilla de la cofradía generosamente financiadas por doña Teresa Enríquez, encomendada a partir de este momento a su capellán Juan de Covarrubias, tras la fase inicial en que dicha labor aparecía encomendada a Rodrigo de Salinas, como ya se ha señalado.

El 28 de agosto Juan de Covarrubias contrata con "magister Aloysius Venetus, machinator, habitator Vrbis"63, la realización del pavimento de la capilla ("¿ad

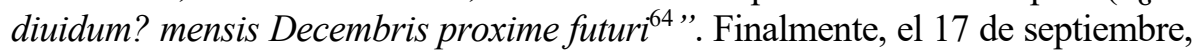

jn pariete vbi est fenestra cum certis pilastris decuratis cum certis frisis omnj meliori modo quo fieri poterit et in deto pariete erunt certe prospectiue in paiese de bonis coloribus factis omni meliori modo toccatis de auro vbi opus erit. Item quod extra dictam capellam a parte anteriori sit testudo dealbata usque ad mediam testudinem alterius capelle. Item omnes bastis pilastrorum in capella sint depicte de dias pro per totum presentem annum millesimum quingentesimum octauum" (Roma, 4-agosto-1508, ante Ascanio Marso; fols. 14r-15r). Brevemente extractado en VALTIERI, S., La Basilica di S. Lorenzo in Damaso..., p. 60: "I contratti stipulati con vari artisti vanno dal 1507 al 1509: (...) il 4 agosto 1508 e il 17 successivo i pittori romani Paolo e Silvestro Solange (o Falange) per 230 ducati si impegnano nelle opere ornamentali e per 42 ducati dorano i parapetti").

${ }^{63}$ VALTIERI, S., La Basilica di S. Lorenzo in Damaso..., pp. 60-61: "Questa notizia assume una particolare importanza in quanto l'artista può essere identificato con Luigi Pace Veneziano che nel 1516 lavorerà ai mosaici della cupola della cappella Chigi di Raffaello nella chiesa agostiniana di S. Maria del Popolo".

${ }^{64}$ Por 36 ducados, distribuidos en tres pagas al comenzar, mediar y concluir la obra. "[Al margen] «Contrato de solar la capilla de manos y algunas piedras por XXXVI ducados»: [...] facere totum pauimentum capelle Corporis Dominj nostri Ihesuchristi, sita in ecclesia Sancti Laurentij in Damaso de Vrbe, de lapide porphireo serpentino et marmoreo quod pauimentum sit de opere vulgariter nuncupato mandulato grande et mandule minute et triangulato etiam ex eisdem lapidibus paruis et ex alio opere in sextangulo et triangulato etiam ex eisdem lapidibus cum certis frisis minutis exsmalto vitreo serpentino et porphireo cum duobus lapidibus rotundis vno videlit porphireo et altero serpentino quos dictus magister Aloysius sponte donauit eidem capelle et de vno alio opere amigdolarum rotondorum magnitudinis amigdolarum quadrarum magnarum et de quocumque opere fieri poterit ex lapidibus quos omnes lapides prefatus dominus Johannes Couarrubies promisit eidem magistro Aloysio [...] si aliqum lapides ex dictis lapidibus paruus operi predicto deficeret [...] promisit eidem magistro Aloysio [...] dare et consignare 
Juan de Covarrubias contrata con los «spectabiles viri dominj Paulus et Siluester Francisci Falange, fratres, pictores Romani», el dorado de la reja de la capilla, por 40 ducados ${ }^{65}$.

En 1509, último año registrado en el documento que nos ocupa, se registra un hecho seguramente vinculado a la finalización de las obras de la capilla, ya que el 7 de junio, los cofrades, reunidos en San Lorenzo in Damaso, se comprometen con Juan de Covarrubias, como procurador de doña Teresa Enríquez, a conservar perpetuamente todos los bienes de la cofradía ${ }^{66}$. El 10 de agosto otorgan cartas de pago a Juan de Covarrubias «magister Antonius de Robio, laycus Mediolanen. dioc., murator», por la labor de blanquear las capillas circundantes de la capilla de la cofradía, de 15 ducados $^{67}$; y «magister Jacobus Antonius Terrenoue, lignarius, laicus Aretine diocesis», por la ejecución de tres cajones de madera para custodiar los ornamentos donados a la cofradía ${ }^{68}$.

omnes lapides marmoreos magnos pro giuda dicti laborerij [...] et similiter promisit dictus magister Aloysius purgare basamentum dicte capelle jam factum a balagustis jnfra". Incluye el compromiso del artista de proporcionar un diseño del pavimento ("et jnsuper prefatus magister Aloysius promisit dare [...] vnum designum dicti pauimenti in papiro factum"), así como el reconocimiento de haber recibido la primera paga, "occasione prime solutionis predicti pauimenti". Intervienen como fiadores del maestro Aloysius los "spectabilis uir dominus Stephanus quondam magistri Pauli Pellamantelli, ciuis rromanus" (Roma, 28-VIII-1508, ante Ascanio Marso; fols. 15r-16r). Brevemente extractado en VALTIERI, S., La Basilica di S. Lorenzo in Damaso..., p. 60: "Il 28 agosto 1508 Luigi Veneziano per 36 ducati fa contratto per eseguire il pavimento musivo".

65 "[Al margen] «Contrato de pintar las rrexas XL ducados» [...] jnaurare de auro puro et fino duo parapecta capelle Corporis Domini nostri Ihesuchristi, sita in ecclesia Sancti Laurentij in Damaso, jntus et extra, in omnibus locis necessarijs et condecentibus secundum exigentiam dictorum parapettorum, ante festa Natalia proxime futura" (Roma, "in ecclesia Sancti Laurentij in Damaso de Vrbe", 17-noviembre-1508, ante Ascanio Marso; fols. 17r-17v). Actúa como fiador el "honorabilis vir dominus Bernardinus de Vercellis, sutor in Vrbe", cofrade de dicha cofradía. Entre los testigos, destaca el clérigo toledano Alfonso de Tapia / "Alfonso de Tapia, clerico Toletan. diocesis".

66 "omnes confratres dicte societatis... dominj Joseph Paleamenuta, clericum Rossan. et scriptore. Archiui Roman. curie, presentem. et acceptan. secretarium eiusdem societat [...] ad conseruandum, defendendum et manutenendum dictam societatem et eius bona contra quancumque personam ciuiscunque status seu conditionis existat aliaque omnia et singula faciendum, gerendum et exercendum que dicte societati et eius bonis et circa eorum defensionen et augmentum fuerint neccesaria et opportuna" (San Lorenzo in Damaso, 7-junio-1509, ante Ascanio Marso; fols. 17v-18r). Entre los cofrades destacaremos al español Rivera (“dns. Riuiera, hispanus").

67 " [Al margen] «Carta de pago de blanquear las capillas, 15 ducados» [...] ad dealbandam capellas circumcirca capellam Sacratissimj Corporis Dominj nostri Ihesuchristi sitam in ecclesia Sancti Laurentij in Damaso de Vrbe et illas in aliquibus locis matenandum preut cum effectu illas dealbauit et matenauit" ("Rome, in Regione Parionis, in domo habitacionis dnj. Alexandri de Bononia", 10-agosto-1509, ante Ascanio Marso; fols. 20v-21r). Entre los testigos destaca "Johannes Morales, cl. Toletan. diocesis".

68 “"Al margen] «Carta de pago de XIIJ ducados por tres caxones para ornamentos» [...] tres cassonos ligneos cum suis serraturis, quos cassonos idem dns. Johes. donauit capelle societatis 
Un día después, 11 de agosto, le otorgan nuevas cartas de pago los «discreti uiri magistri Johannespaulus et Siluester, eius frater, ac Peregrinus, Romani pictores, por pintar la capilla que está ante dicha capilla de la cofradía, por 30 ducados $^{69}$; y los «discreti uiri magistri Peregrinus et Jeronimus, pictores Romani» por pintar el tabernáculo, por otros $30^{70}$.

El 15 de agosto, el prior, el guardián, el secretario y el camerario de la cofradía realizan inventario de los bienes que Juan de Covarrubias, en nombre de doña Teresa Enríquez, les entregó en $1508^{71}$. El 16 de agosto el prior, el secretario

Corporis Domini nostri Jesucristi, site in ecclesia Sancti Laurentij in Damaso de Urbe, pro reponendis illius paramentis et pannis et alijs rebus eiusdem societatis" ("Rome, in Regione Parionis, in domo habitationis dni. Alexandri de Bononia" (fols. 21v-22r). Entre los testigos destaca "domino Johanne Morales..., clericis Toletan... diocesis".

69 “"Al margen] «Carta de pago de 30 ducados de la capilla que está delante de la principal, pintalla, XXX ducados» [...] ad depingendum capellam que est ante capellam Sacratissimj Corporis Dominj nostri Ihesuchristi existen. in ecclesia Sancti Laurentij in Damaso de Vrbe prout illam depinxerunt" ("Rome, in domo habitacionis dnj. Alexandri de Bononia, in Regione Parionis", ante Ascanio Marsio; fols. 19r-19v).

70 "[Al margen] «Carta pago de 30 ducados de pintar el tavernáculo» [...] ad depingendum tabernaculum in quo reponitur et custoditur Sacratissimum Sacramentum Corporis Dominj nostri Ihesuchristi in capella eiusdem in ecclesia Sancti Laurentij in Damaso de Urbe, de colore azurro et foliagijs cum certis tucchis muntis in campis eiusdem tabernaculi quod prius erant tinc deauratum et planum prout illud pinxerunt" ("Rome, in Regione Parionis, in domo habitationis prefatorum magistri Peregrinij et Jeronimj"; fols. 20r-20v). Entre los testigos destaca "Johanne Morales, clerico Toletan. diocesis".

71 "[Al margen] «Las cosas que di a la Cofadría» [...] donauit et dedit capelle prefate societatis Corporis Domini nostri Jesuchristi ex parte prefate dne. Thiresie de eius commissione et mandato bona infrascripta videlicet: Camisos tres tele de Olanda, cum suis guarmimentis de cremosino in duobus, in tertio de brochato aureo; Item duos alios camisos tele Britannice, cum guarnimentis de cremosino; Item vnm aliun camisum tele de Olanda laboratum de serico negro; Item anuctus sex; Item manipulos sex rasi cremosini; Item sex cingula diuersorum colorum; Item vnam planetam tele de Olanda laboratam de serico nigro; Item duas tunicellas et tunicellam brocati crispi (crespi?) in veluto cremosino; Item duodecim panicellos ad usum purificationis calicis tele de Olanda laboratos de serico; Item unum frontale altaris rasi cremosinj cum guarnimentis de brochato aureo mensure vinus caune? cum dunidio alterius caune?; Item vnum velum cum vna cruce de auro in medio pro altari; Item duodecim corporalia tele de Olanda consecreta; Item sex lras. consecrationis dictorum corporalium, duas in cassulis et alias sine cassulis; Item duo senta argentea cum plagis Domini nostri Jhesucristi ad vsum dandi pacem in ecclesia; Jtem tobalias quatuor tele de Olanda pro altari laboratas de serico nigro; Jtem vnum panum de Cambari laboratum de ffilato albo cum francijs de auro que portat ad collum sacerdos quando portat Sacramentum; Jtem vnam ymaginem in chartam ad ponendum alte altare; Jtem vnam culcitram moriscam laboratam cum vna canua? et palmis quinque rasi cremosinj circumcirca dictam culcitram; Jtem canua. vnam cum duuidio/diundio? rasi cremosini pro tegendis gradibus exutibus super altare dicte ecclesie; Item vnum plumale rasi cremosinj trm. camnar./camiarum? cum vno frigio brochati aurei in quo est historia resurrectionis Domini nostri Jhesucristi; Item vnum cossinum sericen.? ad ponendum sub missali in altare; Item duos cingula, vnum de serico rubeo cum bottonis argenteis et alterum album; «Item duas capsas magnas copertas de corio cum suis ferris; Item vnam patenam magnam argenteam inauratam ad 
y el camerario de la cofradía reconocen haber recibido de Juan de Covarrubias, en nombre de doña Teresa Enríquez, 160 ducados que depositó en el banco de Balduccio y socios, así como otros 39 ducados que les entregó, para la adquisición de una casa ${ }^{72}$.

Consta, asimismo, por dos sobradamente conocidas cartas de pago giradas en Toledo por "Alonso de Covarruvyas, maestro de cantería, vecino de la muy noble çibdad de Toledo" a mercaderes genoveses, la presencia de "Juan de Couarruuyas, my hermano, capellán de la señora doña Theresa Enríques" en Roma aproximadamente entre septiembre de 1514 y mayo de $1515^{73}$. Desconocemos si su estancia en Roma al servicio de la señora de Torrijos se prolongó hasta entonces o si por el contrario se correspondería con un nuevo viaje a la Ciudad Eterna ${ }^{74}$.

\section{CONCLUSIÓN}

Si bien todos los indicios apuntan a que su etapa en Guadalajara y la incursión con la familia Mendoza, mecenas por antonomasia de las nuevas formas, fue el punto de inflexión y progresivo cambio en la manera de hacer, no cabe obviar la hipotética existencia de obra desconocida de Alonso de Covarrubias, imaginero "a lo moderno", bajo la dirección de los Egas, y posiblemente bajo el mecenazgo de don Gutierre de Cárdenas y en particular de doña Teresa Enríquez, no menos importante pues imprimió carácter en nuestro artista. Gracias a la vinculación con esta señora pudo viajar a Roma, al menos como testigo de la evolución de una de sus más renombradas obras pías (muy probablemente, por el estrecho vínculo de su hermano Juan de Covarrubias con la devota señora

visitandum reliquias Corporis Dominj nostri Jesucrhisti celebrata missa; Item centum viginti perlas perforatas, inter magnas et paruas, ex quibus maiores ponantur in tabernaculo in quo portatur Sacramentum relique ponantur in vna bursa in qua reponetur dicta patena» [...]. Que omnia et singula bona supradicta prefati dni. prior, guardiani, secretarius et camerarius attestati fuerunt et attestantur fuisse et esse in dicta capella inter alia bona ipsius capelle" ("Rome, in regione Parionis, in ecclesia Sancti Laurentij in Damaso", 15-agosto-150, ante Ascanio Marsio; fol. $18 v)$. Es testigo "Sanctio Cota, clerico toletano".

72 [Al margen] "«Carta de pago de CLX ducados / XXXIX ducados para conprar la casa»" ("Rome, in Regione Parionis, in domo dicti domini Bernardum Puntibus"; fols. 22r-22v). Son testigos los "honorabilibus uiris dominis Petro López da Anguione, clerico Toletan. diocesis, et Johanne Morales, eiusden diocesis".

${ }^{73}$ GÓMEZ MENOR Y FUENTES, J., "Algunos documentos inéditos de Juan de Borgoña y de otros artífices toledanos de su tiempo", Anales Toledanos, 2 (1968) 163-183 y 168-169.

${ }^{74}$ García Rey también presenta un documento, esta vez del año 1525 y custodiado en el Archivo Histórico Provincial de Toledo, por el que Alonso de Covarrubias se obliga a pagar a Bautista Negrón, Antonio Suyle y Benito Centurión, genoveses, 33.000 mrs. por otros tantos que de ellos recibió, por una cédula de crédito de 100 ducados, girada a Lázaro de Grimaldo en favor de su hermano Juan de Covarrubias, residente en Roma, en GARCÍA REY, V., Arquitectura, 97 (1927) 171. 
de Torrijos, desde el origen mismo de su gestación en Torrijos, pasando por su fundación, dotación, supervisión de la construcción arquitectónica y ornamentación, etc.). No podemos determinar por el momento si se trató de un verdadero viaje de estudios, análogo al que emprendieron nuestras otras "águilas" 75 , pero sí que cabe asegurar que conoció de primera mano lo que se estaba haciendo en Italia. Gracias a este documento clave que confirma al menos su presencia en la Ciudad Eterna y el contacto directo con el arte que allí se estaba desarrollando en los años cruciales de comienzos del siglo XVI, de una manera tangible, sin duda mucho más allá de las limitadas miras que proporcionaban libros o grabados.

La información que deriva del documento aquí presentado es clave para iniciar una investigación más profunda que podría aportar ulteriores conocimientos sobre la estancia del maestro Covarrubias en la Ciudad Eterna. También cabe plantearse hasta qué punto tan significativa novedad implicará la necesidad de emprender una revisión, en clave romana, de la extensísima obra del inmortal genio toledano, merced a la luz aportada por una aparentemente insignificante cita en tan amplio documento.

\section{FUENTES Y BIBLIOGRAFÍA}

\section{Fuentes manuscritas}

- ADB, PSM Blanca, Leg. 16-53 y 54

- AHNOB, BAENA, C.200, D.8

- BAENA, C. 391, D. 22-23

- BAENA, C.4, D.44

- BAENA, C.48, D. 1

- BNE, Mss/9168, Descripción de el sumo y máximo templo de la Santa Iglesia de Toledo y de todas las demás cosas que en el hai dignas de sauerse, por el doctor Blas Ortiz, Canónigo de la dicha Santa Iglesia, Toledo, 1546.

${ }^{75}$ Cabe preguntarse si -más allá de la base que ofrecía Francisco de Holanda en sus tablas de famosos pintores y "esculptores de mármor" modernos a quien llaman 'águilas', insertas en su tratado De Pintura Antiga (manuscrito de 1548; versión en castellano de Manuel Denis 1563)-, el elenco de 'águilas' elegido por Gómez-Moreno para sobrevolar las cumbres de nuestro Renacimiento, seguido unánimemente por la historiografía hispánica, así como la exclusión de artistas supuestamente menos dotados o que, al menos, no dejaron huella documental de su estancia, más o menos prolongada, en la Península Itálica, hubiese variado de conocerse tan temprano viaje a Roma. Véase GÓMEZ-MORENO, M., Las Águilas del Renacimiento español: Bartolomé Ordóñez, Diego Silóee, Pedro Machuca, Alonso Berruguete. CSIC. Madrid 1941. 


\section{Fuentes impresas}

- ARFE Y VILLAFAÑE, De varia conmensuración para la esculptura y arquitectura, Sevilla 1585.

- EIXIMENIS, FRANCESC, Carro de las donas, Valladolid 1542.

- FANUCCI, C., Trattato di tutte l'opere pie dell'alma cita di Roma, Roma 1601.

\section{Bibliografía}

- ALARCÓN, M.A., Biografía compendiada de la Excelentísima Señora Doña Teresa de Enríquez llamada 'la loca del Sacramento', Valencia 1893.

- Apuntes históricos sobre la villa de Torrijos (Toledo) y sus más esclarecidos bienhechores, Valencia 1894.

- Apuntes históricos sobre la "loca del Sacramento" y la villa de Torrijos, Toledo 1928.

- AZCÁRATE RISTORI, J.M., “Antón Egas”, en BSAA (Valladolid), 23 (1957) 5-17.

- Escultura del siglo XVI, Ars Hispaniae, Madrid 1958, t. XII.

- "Sentido y significación de la arquitectura hispanoflamenca en la corte de Isabel la Católica", en BSAA (Valladolid), 37 (1971) 201-223.

- BAYLE, C., La loca del Sacramento: Doña Teresa Enríquez, Madrid 1922.

- CATILINA Y DEL AMO, S., Roma: obra póstuma de Severo Catilina por Francisco Cutanda, Madrid 1873.

- CASTILLO, M.A., El renacimiento y el manierismo en España, Historia 16, Madrid 1999, t. XIX.

- CASTRO SANTAMARÍA, A., "Un error de Llaguno que se arrastra hasta nuestros días: la supuesta visita a la Catedral de Segovia de los maestros Álava, Covarrubias, Egas y Bigarny en 1529, en Anuario del Departamento de Historia y Teoría del Arte (Madrid), VI (1994). 
- CHUECA GOITIA, F., Arquitectura del siglo XVI, Ars Hispanie, Madrid 1953, t. XI.

- DURÁN SAMPERE, A., y AINAUD DE LASARTE, J., Escultura Gótica, Ars Hispaniae, Madrid 1956, t. VIII.

- FERNÁNDEZ FERNÁNDEZ, A., Teresa Enríquez: la loca del Sacramento, B.A.C, Madrid 2001.

- FOLIANA FERRÁNDEZ, N., "Ornamentos litúrgicos encargados por la reina Isabel la Católica a Covarrubias (1488), en Estudios sobre patrimonio, cultura y ciencias medievales, 2 (2016) 495-550.

- GARCÍA REY, V., "La puerta nueva de Bisagra", en Arquitectura, 37 (1922) 191-195.

- "La portada de la Iglesia del Monasterio de san Clemente el Real de Toledo", en Arquitectura 79 (1925) 249-254.

- "El famoso arquitecto Alonso de Covarrubias: datos inéditos de su vida y obras", en Arquitectura, 97 (1927) 167-175; 98 (1927) 207-212; 101 (1927) 311-319; 103 (1927) 375-380; 104 (1927) 415-420; 1051 (1928) 3-7; 107 (1928) 95-99; 110 (1928) 202-203; 111 (1928) 236-237; 112 (1928) 297-299; 114 (1928) 331.

- GÓMEZ-MORENO, M., Las Águilas del Renacimiento español: Bartolomé Ordónez, Diego Silóee, Pedro Machuca, Alonso Berruguete. CSIC, Madrid 1941.

- LOGONBARDO CARRILlO, J., y BUITRAGO MASELLI, J., La Colegiata de Torrijos, Toledo 1999.

- LONGOBARDO CARRILlO, J., Alonso de Covarrubias y Leyva: vida y obra del más ilustre hijo de la villa de Torrijos, Toledo 2018.

- LLAGUNO AMIROLA, E., Noticias de los arquitectos y arquitecturas de España desde su restauración, Ilustradas y acrecentadas con notas, adiciones y documentos por Juan Agustín CEAN-BERMÚNDEZ, Imprenta Real, Madrid 1829, t. I-IV.

- LÓPEZ TORRIJOS, R., y NICOLAU CASTRO, J., "La familia Cárdenas, Juan de Lugano y los encargos de la escultura genovesa en el siglo XVI", en BSAA (Valladolid), 68 (2002) 169-190. 
- MARÍAS FRANCO, F., El siglo XVI: gótico y renacimiento, Madrid 1992.

- MARCOS RODRÍGUEZ, F., "Don Diego de Cobarrubias y la Universidad de Salamanca", en Salmanticensis (Salamanca), 6 (1959) 37-85.

- MARTÍNEZ MONTERO, J., "Nuevas aportaciones a la historia constructiva de la escalera del Hospital de Santa Cruz en Toledo", en De Arte: revista de historia del arte (León), 12 (2013).

- MARTÍNEZ VEGA, R., La catedral de Toledo y la santísima Virgen, en Toletum (Toledo), 54 (1933) 11- 48.

- MIRANDA CALVO, J., “Alonso de Covarrubias en los documentos”, en Militaria: revista de cultura militar (Madrid), 2 (1990).

- MORALES CANO, S., Símbolos, formas y espacios de la escultura gótica funeraria en Castilla - La Mancha: Toledo. Tesis doctoral dirigida por Miguel Cortés Arrese, Cuenca 2009.

- MORALES MARTÍNEZ, A. J., "Tradición y modernidad, 1526-1563”, en Arquitectura del Renacimiento en España, 1488-1599, Madrid 1989, pp. 97-237.

- OSABA, R., La loca del Sacramento o doña Teresa Enríquez, Ávila 1926.

- PARRO, S.R., Toledo en la Mano, descripción histórico-artística de la magnifica catedral y de los demás célebres monumentos, Toledo 1857, t. I.

- PEDRAZA RUIZ, E., "Covarrubias en los documentos del Archivo Municipal de Toledo", Toletum. Boletín de la Real Academia de Bellas Artes y Ciencias Históricas de Toledo (Toledo), 25 (1990) 27-36.

- SÁNCHEZ PASO, J.A. (edición, introducción y notas), Crónica burlesca del Emperador Carlos V, Universidad de Salamanca, Salamanca 1989.

- SANTOS VAQUERO, A., y SANTOS MARTÍN, A., Alonso de Covarrubias: el hombre y el artifice, ed. Azacanes, Toledo 2003.

- TOLEDO. Revista de Arte (Toledo), 187 (1922).

- TORRES BALVÁS, L., Arquitectura Gótica, Ars Hispaniae, Madrid 1952, t. VII. 
- VALTIERI, S., La Basilica di S. Lorenzo in Damaso nel palazzo della Cancelleria a Roma, attraverso il suo archivio ritenuto scomparso, Roma 1984. 